\title{
Sensitivity or resistance to steroid therapy in children with idiopathic nephrotic syndrome is not associated with polymorphism of angiotensin converting enzyme (ACE)
}

\author{
Parisadat Ahmadi ${ }^{1}$, Rozita Hoseini ${ }^{2}$, Parvaneh Rahimi-Moghaddam ${ }^{3 *}$, Seyyed Amir Yasin Ahmadi ${ }^{4}$ \\ ${ }^{1}$ Student Research Committee, Iran University of Medical Sciences, Tehran, Iran. \\ ${ }^{2}$ Department of Pediatrics, Iran University of Medical Sciences, Tehran, Iran. \\ ${ }^{3}$ Department of Pharmacology, Iran University of Medical Sciences, Tehran, Iran. \\ ${ }^{4}$ Student Research Committee, Lorestan University of Medical Sciences, Khorramabad, Iran.
}

\begin{tabular}{l} 
ARTICLE INFO \\
\hline Article history: \\
Received on: $06 / 09 / 2016$ \\
Revised on: 29/09/2016 \\
Accepted on: $26 / 10 / 2016$ \\
Available online: $28 / 12 / 2016$ \\
\hline Key words: \\
Nephrotic syndrome, \\
angiotensin converting \\
enzyme, steroid therapy.
\end{tabular}

\section{INTRODUCTION}

It's about years that the relation between renin angiotensin aldosterone system (RAS) and involving enzymes such as angiotensin converting enzyme (ACE) with nephrotic syndrome is under the focus of researchers and also there are a lot of meta-analyses (Ai et al., 2016; Cargnin et al., 2015). As an introduction, ACE is a renal-pulmonary enzyme which converts angiotensin-1 (the inactive form of the enzyme) to angiotensis-2 (the active form of the enzyme acts as a vasoactive peptide). Hence, over expression of ACE could result in higher levels of angiotensin-2 that in turn

\footnotetext{
* Corresponding Author

Parvaneh Rahimi-Moghaddam, Department of Pharmacology, University of Medical Sciences, Tehran, Iran.

Email: rahimi.p@iums.ac.ir
}

leads to hemodynamic complications of kidneys (Bernstein et al., 2016) such as glomerulosclerosis (Beer et al., 2016). Other than playing the blood filtering role, kidneys are a part of the endocrine system that the RAS is the best example for this fact (Ahmadi, et al., 2016; Nasri, 2015). In other words, RAS controls blood pressure, volume and electrolyte (Anderson et al., 2016). Other than the items above, RAS plays a role in hematopoiesis and other physiological processes of human body (Kim et al., 2016). In this endocrine system, in response to reduction of electrolyte level, blood volume and blood pressure, podocytes - the cells limiting plasma passing in glomerulus with help of their foot processes surrounding the capillaries and their penetrations to make the glomerular barrier (Hajhosieni et al., 2014)-and juxtaglomerular apparatus release the hormone renin (Nasri, 2015). In blood, renin in turn converts the angiotensinogen produced by liver to angiotensin-1. 
In response to reduction of electrolyte, volume and pressure of blood, juxtaglomerular apparatus release renin in blood. Renin in turn impacts on angiotensinogen in liver and converts it to angiotensin I.

The angiotensin I converts to angiotensin II by the ACE presenting and acting in pulmonary circulation. Therefore, hypoxic injuries to lungs could results in imbalance of ACE. The angiotensin II in turn results in increase of feeling thirsty, intestinal salt absorption, aldosterone releasing from adrenal glands, maintaining salts and water by kidneys, increasing cardiac output, etc. (Gralinski et al., 2016).

The most famous type of nephrotic syndrome are minimal changing, and focal and segmental glomerulosclerosis (FSGS) (Inaba et al., 2016). This disease is the most commonplace kidney disease in children (Elie et al., 2012; Yildiz et al., 2013). The disease is usually primary and sometimes is secondary to metabolic, systemic (Lee et al., 2016) or inflectional reasons (Chan et al., 2016). Up to now, a lot of involving genes have been identified. Outbreak of nephrotic syndrome in Europe and the US gets to 16 out of 10000 children (Benoit et al., 2010). This disease gets to end-stage in about 10-20\% of the patients (Antignac, 2002). Relapse of the disease is commonplace and usually occurs 14 days after transplantation (Antignac, 2002). Patients with nephrotic syndrome are at risk of thrombo-emboli due to hemostatic disorders. It seems that crossing of heavy proteins triggers the coagulation cascade (Sagripanti and Barsotti, 1995).

Because of anti-inflammatory effects of the steroids, they are used for treatment of nephrotic syndrome in children. Individuals with nephrotic syndrome divided into two groups of sensitive and resistant to steroid therapy (Braun et al., 2016). Among them about $90 \%$ are sensitive to steroid therapy (Benoit et al., 2010).

ACE has two allelic forms of insertion (I) and deletion (D). It has been proved in a lot of meta-analyses that severity of nephrotic syndrome is associated with the genotype DD followed by ID (El-Gayar et al., 2015). So we intend to find that whether sensitivity or resistance to steroid therapy is associated with ACE polymorphism or not.

\section{METHODS}

In the current study we used randomized sampling. The sample size was 40 children ( 20 boys and 20 girls). Among them, 22 patients were sensitive and 18 patients were resistant to steroid therapy. The samples were collected from Ali-Asghar pediatric hospital in Tehran, Iran. This study had been approved by ethic committee of Iran University of Medical Sciences.

After getting the written consents from the parents of the children, we collected blood samples from them. Then we used polymerase chain reaction (PCR) for the genotyping. After collection of the results from electrophoresis on $1 \%$ agarose gel (figure 1), we used Chi-squared test for statistical analysis with considering $\mathrm{P}=0.05$ as the significance level.

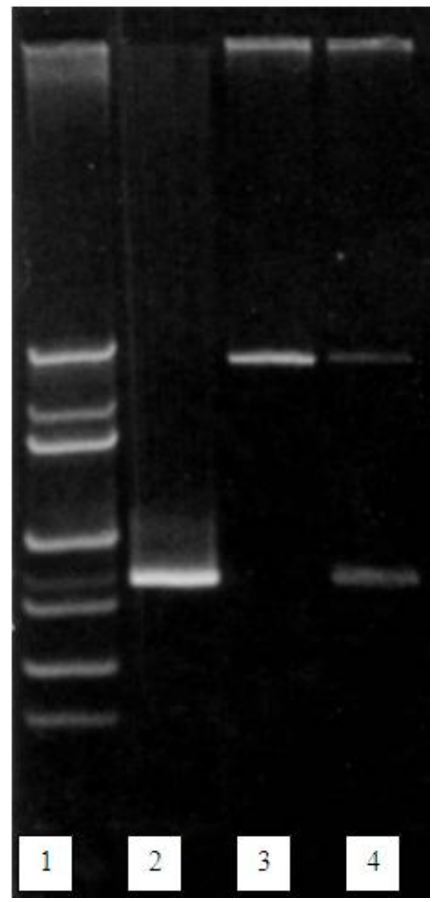

Fig. 1: The results on the 1\% agarose gel. 1) DNA indicator ( $\varphi$ X174 HaeIII cleaved $\mathrm{M}_{\mathrm{r}}$ ); 2) DD genotype; 3) II genotype; 4) ID genotype.

\section{RESULTS AND DISCUSSION}

The statistical analysis showed no significant correlation between ACE polymorphism and sensitivity or resistance to steroid therapy (figure 2$)(\mathrm{P}=0.77)$. Although the frequency of DD genotype was higher in the resistant group, but this difference was not statistically significant. The results of our study in Iran, shows no significant relation. Ahmed El-Gayar et al. in Egypt found that the frequency of DD genotype was higher in steroid resistant patients, of course in adults (El-Gayar et al., 2015). In the study of Öktem et al done on children, DD genotype was more frequent in patients group; but there was no assessment between resistant and sensitive patients (Öktem et al., 2004). There were just few studies compared ACE polymorphism with resistance or sensitivity to steroid therapy that most of them were reanalyzed in a meta-analysis done by Zhou et al. (2011). They found that ACE polymorphism cannot predict the sensitivity or resistance to steroid therapy in children with idiopathic nephrotic syndrome.

Kidney injuries are serious conditions with serious consequences if failed to diagnose on time. Hence, finding diagnostic tests for prevention of kidney injuries is necessary (Poorshahbaz et al., 2015). As a strategic prevention program for low-income countries, governments are supposed to give insight and awareness to their people about screening tests (Perico and Remuzzi, 2016). However based on the findings of ours and previous researchers' the PCR cannot be used for prediction of the sensitivity or resistance to steroid therapy, but the PCR test for prediction of nephrotic syndrome in children with familial history is necessary to take prophylactic measures. 


\begin{tabular}{|c|c|c|c|c|}
\hline & \multicolumn{3}{|c|}{$\begin{array}{l}\text { Relation of sesitivity to steroid therapy with ACE } \\
\text { genotype. }\end{array}$} & \\
\hline & II & ID & DD & \\
\hline Sensitive & $\begin{array}{c}12 \\
11.55 \\
(0.02)\end{array}$ & $\begin{array}{c}8 \\
7.70 \\
(0.01)\end{array}$ & $\begin{array}{c}2 \\
2.75 \\
(0.20)\end{array}$ & 22 \\
\hline Resistant & $\begin{array}{c}9 \\
9.45 \\
(0.02)\end{array}$ & $\begin{array}{c}6 \\
6.30 \\
(0.01)\end{array}$ & $\begin{array}{c}3 \\
2.25 \\
(0.25)\end{array}$ & 18 \\
\hline & 21 & 14 & 5 & 40 \\
\hline
\end{tabular}

$\chi^{2}=0.519, \quad$ df $=2, \quad \chi^{2} / \mathrm{df}=0.26, \quad \mathrm{P}\left(\chi^{2}>0.519\right)=0.7713$

Fig . 2: The statistical results.

\section{CONCLUSION}

Finally we found that although based on previous studies, $\mathrm{D}$ allele and DD genotype are more frequent in children with idiopathic nephrotic syndrome in comparison to healthy children, but the resistance or sensitivity to steroid therapy in children is not associated with ACE polymorphism. Further meta-analysis on the studies done on children is suggested.

\section{Financial support and sponsorship: Nil.}

Conflict of Interests: There are no conflicts of interest.

\section{REFERENCES}

Ahmadi S. A. Y., Ahmadi P. S., Tavafi M., and Hasanvand A. Vascular Endothelial Growth Factor (VEGF) and Its Controversies about Nephrotic Syndrome and Diabetic Nephropathy: A Systematic Review. Int J Intg Med Sci, 2016; 3, 229-231.

Ai JW, Zeng XT, Liu Y, Fu Y, Liu TZ, and Pei B. Association between angiotensin converting enzyme gene insertion/deletion polymorphism and renal scar risk in children vesicoureteral reflex: a reappraise meta-analysis. Scientific Reports, 2016; 6, 31243.

Anderson CE, Li C, He J, Rao DC, Hixson JE, Gu D, Chen J. Abstract P263: Resequencing Study Identifies Renin-AngiotensinAldosterone System Genes and Novel Low Frequency Variants Associated with Blood Pressure Salt-sensitivity. Circulation, 2016; 133, AP263AP263.

Antignac C. Genetic models: clues for understanding the pathogenesis of idiopathic nephrotic syndrome. The Journal of clinical investigation, 2002; 109, 447-449.

Beer A., Mayer G., and Kronbichler A. Treatment Strategies of Adult Primary Focal Segmental Glomerulosclerosis: A Systematic Review Focusing on the Last Two Decades. BioMed research international, 2016; 2016.

Benoit G., Machuca E., and Antignac C. Hereditary nephrotic syndrome: a systematic approach for genetic testing and a review of associated podocyte gene mutations. Pediatric Nephrology, 2010; 25, $1621-1632$

Bernstein K. E., Khan Z., Giani J. F., Zhao T., Eriguchi M., Bernstein E. A., Shen X. Z. Overexpression of angiotensin-converting enzyme in myelomonocytic cells enhances the immune response. F1000Research, 2016; 5, F1000 Faculty Rev-1393.

Braun D. A., Sadowski C. E., Kohl S., Lovric S., Astrinidis S. A., Pabst W. L., Shril S. Mutations in nuclear pore genes NUP93, NUP205 and XPO5 cause steroid-resistant nephrotic syndrome. Nature genetics, 2016; 48, 457-465.

Cargnin S., Quaglia M., Canonico P. L., Stratta P., and Terrazzino S. Impact of recipient ACE I/D genotype on kidney function in renal transplant patients: a meta-analysis of cross-sectional and longitudinal studies. Pharmacogenomics, 2015; 16, 1887-1902.

Chan C.Y., Liu I. D., Resontoc L. P., Ng K.-H., Chan Y.-H., Lau P. Y. W., Yeo W.-S. T Lymphocyte Activation Markers as Predictors of Responsiveness to Rituximab among Patients with FSGS. Clinical Journal of the American Society of Nephrology, 2016; CJN. 11941115.

El-Gayar H. A., El-Dahtory F., El-Gamal E., and Hamed S. ACE Gene Polymorphism Frequency in Steroid Resistance and Steroid Sensitive in Patients with Idiopathic Nephrotic Syndrome. International journal of science and research, 2015; 5, 90-94.

Elie V., Fakhoury M., Deschênes G., and Jacqz-Aigrain E. Physiopathology of idiopathic nephrotic syndrome: lessons from glucocorticoids and epigenetic perspectives. Pediatric Nephrology, 2012; $27,1249-1256$.

Gralinski M., Neves L. A., and Tiniakova O. ReninAngiotensin System. Drug Discovery and Evaluation: Pharmacological Assays, 2016; 665-707.

Hajhosieni L., Fallah Rostami F., and Khaki A. Bioflavonoids Effects of Ginger on Glomerular PodocyteApoptosis in StreptozotocinInduced Diabetic Rat. Crescent Journal of Medical and Biological Sciences, 2014; 1, 42-45.

Inaba A., Hamasaki Y., Ishikura K., Hamada R., Sakai T., Hataya H., Honda M. Long-term outcome of idiopathic steroid-resistant nephrotic syndrome in children. Pediatric Nephrology, 2016; 31, 425-434.

Kim S., Zingler M., Harrison J. K., Scott E. W., Cogle C. R., Luo D., and Raizada M. K. Angiotensin II Regulation of Proliferation, Differentiation, and Engraftment of Hematopoietic Stem Cells. Hypertension, 2016; 67, 574-584.

Lee Y. H., Kim E. Y., Kim Y.G., Lee S.-H., Song R., Yang H. I., . . . Lee S.-H. Complete Remission of Nephrotic Syndrome Without Resolution of Amyloid Deposit After Anti-Tumor Necrosis Factor $\alpha$ Therapy in a Patient With Ankylosing Spondylitis. JCR: Journal of Clinical Rheumatology, 2016; 22, 86-88.

Nasri H. Journal of Renal Endocrinology; the kidney as an endocrine organ. Journal of Renal Endocrinology, 2015; 1.

Őktem F., Şirin A., Bilge I., Emre S., Ağaçhan B., and Ispir T. ACE I/D gene polymorphism in primary FSGS and steroid-sensitive nephrotic syndrome. Pediatric Nephrology, 2004; 19, 384-389.

Perico N., and Remuzzi G. Prevention programs for chronic kidney disease in low-income countries. Internal and emergency medicine, 2016; 11, 385-389.

Poorshahbaz F., karami A., Jozpanahi M., Pezeshki A., Fagihzadeh S., Esmailzadeh A., Kashkuli M. Comparison of Changes in Serum Creatinine and PNGAL in Predicting Renal Damage in Brucellosis Patients Receiving Gentamycin. Crescent Journal of Medical and Biological Sciences, 2015; 2, 116-120.

Sagripanti A., and Barsotti G. Hypercoagulability, intraglomerular coagulation, and thromboembolism in nephrotic syndrome. Nephron, 1995; 70, 271-281.

Yildiz B., Cetin N., Kural N., and Colak O. CD19+ CD23+ B cells, CD4+ CD25+ T cells, E-selectin and interleukin-12 levels in children with steroid sensitive nephrotic syndrome. Italian journal of pediatrics, 2013; 39, 1 .

Zhou T. B., Qin Y.H., Su L.N., Lei F.Y., Huang W.F., and Zhao Y.-J. ACE I/D gene polymorphism can't predict the steroid responsiveness in Asian children with idiopathic nephrotic syndrome: a meta-analysis. PLoS One, 2011; 6, e19599.

\section{How to cite this article:}

Ahmadi P, Hoseini R, Rahimi-moghaddam P, Ahmadi SAY. Sensitivity or resistance to steroid therapy in children with idiopathic nephrotic syndrome is not associated with polymorphism of angiotensin converting enzyme (ACE). J App Pharm Sci, 2016; 6 (12): 206-208. 